\title{
Unusual Tissue - Unusual Issue: Pancreatic Heterotopia Presenting as Gastric Outlet Obstruction
}

\author{
Thu L. Nguyen ${ }^{a} \quad$ Shivani Kapur ${ }^{a} \quad$ Stephen C. Schlack-Haerer ${ }^{b}$ \\ Grzegorz T. Gurdac, d Milan E. Folkers ${ }^{\mathrm{b}}$
}

aDivision of Medical Education, Department of Internal Medicine, Gundersen Health System, La Crosse, WI, USA; 'bivision of Gastroenterology and Hepatology, Department of Internal Medicine, Gundersen Health System, La Crosse, WI, USA; 'Department of Pathology, Gundersen Health System, La Crosse, WI, USA; ${ }^{d}$ Gundersen Medical Foundation, Kabara Cancer Research Institute, La Crosse, WI, USA

\section{Keywords}

Pancreatic heterotopia · Ectopic pancreas · Gastric outlet obstruction

\begin{abstract}
Pancreatic heterotopia $(\mathrm{PH})$ is a common, but typically small $(<1 \mathrm{~cm})$, incidental and asymptomatic finding; however, $\mathrm{PH}$ should be considered even for large and symptomatic upper gastrointestinal masses. A 27-year-old white woman presented with a 3-week history of burning epigastric pain, nausea, early satiety, and constipation. Physical examination revealed epigastric and right upper quadrant tenderness with normal laboratory workup, but imaging revealed a $5-\mathrm{cm}$, partly cystic mass arising from the gastric antrum with resulting pyloric stenosis and partial gastric outlet obstruction. Endoscopic ultrasound-guided fine needle aspiration revealed $\mathrm{PH}-$ an anomalous pancreatic tissue lying in a nonphysiological site. The patient ultimately underwent a resection and recovered uneventfully, with a complete pathologic examination revealing normal exocrine pancreatic tissue ( $\mathrm{PH}$ type 2) without malignant transformation. We report a case of heterotopic pancreas manifesting as severe gastric outlet obstruction, in addition to a thorough diagnostic workup and surgical follow-up, in a young adult Differential diagnoses and features that speak to benignity of a large, symptomatic mass lesion $(\mathrm{PH}$ in particular) are discussed.




\section{Case Reports in Gastroenterology}

Case Rep Gastroenterol 2021;15:338-343

DOI: $10.1159 / 000512427$

(c) 2021 The Author(s). Published by S. Karger AG, Basel www.karger.com/crg

Nguyen et al.: Pancreatic Heterotopia Presenting as Gastric Outlet Obstruction

\section{Introduction}

Gastric outlet obstruction encompasses a wide range of conditions including peptic ulcer disease, Crohn's disease, caustic ingestion, large gastric polyps, gastric bezoars, malignancy, and anatomic variants such as annular pancreas. Pancreatic heterotopia (PH) is another anatomic variant, lacking vascular and direct physical connection with the functional pancreas organ, yet with typically apparently normal exocrine (and sometimes endocrine islet) tissue histomorphology. PH is typically found in the distal stomach, duodenum, or proximal jejunum, and more rarely within Meckel's diverticulum, the gallbladder, bile ducts, and minor and major papillae [1]. Most patients with PH are asymptomatic; however, some can develop abdominal pain, gastrointestinal bleeding, or pancreatitis [2-4]. Here, we highlight another possible complication of PH: gastric outlet obstruction.

\section{Case Report}

A 27-year-old, previously healthy white woman presented with a 3-week history of burning epigastric pain, nausea, early satiety, and constipation. Abdominal examination revealed epigastric and right upper quadrant tenderness, without any obvious palpable masses. An abdominal ultrasound to evaluate the gallbladder and liver was unrevealing. The results of a laboratory workup including complete blood count, liver function tests, amylase, and lipase were all within normal limits. A contrast-enhanced CT scan showed a 5 -cm, partly cystic mass arising from the gastric antrum manifesting as pyloric stenosis leading to a partial gastric outlet obstruction (Fig. 1).

The patient shortly underwent an esophagogastroduodenoscopy (EGD), which demonstrated a single, inflamed, umbilicated prepyloric mass with a positive pillow sign, highly specific $(>95 \%)$ for an underlying mass (Fig. 2). Endoscopic ultrasound (EUS) showed a well-defined, hypoechoic, but heterogeneous $36 \times 25 \mathrm{~mm}$ antral mass without obvious cystic features. An intact interface between the mass and surrounding structures also suggested a well-defined, round lesion without overt signs of invasion (Fig. 2).

Despite the large size of the mass, the lack of lymphadenopathy, no family history of cancer, and no known genetic predispositions made it less likely to be an epithelial malignancy (gastric or pancreatic carcinoma). However, a neuroendocrine neoplasm or a rare mixed adenoneuroendocrine carcinoma remained in the differential. Other possible perigastric neoplasms included: lipomatous and neural-derived (schwannoma, neuroma, or neurofibroma) tumors, leiomyoma, and gastrointestinal stromal tumor. The differential diagnoses for the nonneoplastic gastric mass under consideration were a lymphangioma, aberrant pancreas (i.e., incomplete annular pancreas), and ectopic pancreatic tissue. EUS-guided fine needle aspiration (FNA) of the umbilicated prepyloric mass revealed a submucosal pancreatic parenchyma compatible with ectopic pancreatic tissue (Fig. 3a).

The patient's symptoms improved with bowel rest, and she was slowly able to tolerate a regular diet. She was discharged home with advice to maintain hydration and avoid alcohol. On subsequent follow-up visits, she continued to endorse persistent intermittent symptoms of nausea, abdominal pain, and early satiety, unlike most cases of PH. The patient eventually underwent robotic antrectomy with Billroth I reconstruction approximately 3 months after the initial diagnosis. A resulting surgical pathology specimen confirmed the FNA-based

\section{Karger'=}




\section{Case Reports in Gastroenterology}

\begin{tabular}{l|l}
\hline Case Rep Gastroenterol 2021;15:338-343 \\
\hline DOI: 10.1159/000512427 & $\begin{array}{l}\text { @ 2021 The Author(s). Published by S. Karger AG, Basel } \\
\text { www.karger.com/crg }\end{array}$ \\
\hline
\end{tabular}

Nguyen et al.: Pancreatic Heterotopia Presenting as Gastric Outlet Obstruction

cytopathology diagnosis of heterotopic exocrine pancreatic tissue (Fig. 3b, c). The patient recovered well without any postoperative complications.

\section{Discussion}

$\mathrm{PH}$ is most commonly diagnosed within the middle-age group (30- to 50-year-olds), and more commonly in men. It is usually an incidental finding on a CT scan or during EGD, occurring at a rate of $0.5-13.7 \%$ in the general population $[4,5]$. The condition should be included in the differential diagnosis of a submucosal prepyloric mass in any patient, even without elevated digestive enzyme (amylase, lipase, and tryptase) serum levels. It may become clinically evident when complicated by pain due to bleeding, pancreatitis, and/or obstruction. Malignant transformation of $\mathrm{PH}$ is exceedingly rare, with a reported incidence of $<1 \%$ [4-6].

On EGD, PH usually appears as an umbilicated, submucosal mass in the gastric antrum, although it can be found in any location in the stomach (25-60\%) or proximal duodenum (25$35 \%)[7,8]$. The diagnosis is typically based on a classic appearance, but in the case of complications or an atypical location, EUS-guided FNA may be necessary to formally establish the diagnosis. Endosonographic findings of PH typically include a hypoechoic, heterogeneous mass without invasive features and usually with indistinct margins and anechoic areas within the lesion correlate with ductal structures [8,9].

Asymptomatic ectopic pancreatic lesions with low suspicion for malignancy can be followed expectantly. However, resection of ectopic tissue is recommended for bothersome symptoms, particularly if it can be safely carried out by minimally invasive techniques, depending on the size and anatomic location [10].

\section{Acknowledgements}

The authors would like to thank Dr. Travis Smith (general surgery), Dr. Richard J. Wittchow (gastrointestinal pathology), and Dr. Molly Van Appledorn (assistance with edits and images) for their advice and contributions.

\section{Statement of Ethics}

The institutional review board for human subject research at Gundersen Health System reviewed and approved this case report for publication. To the best of our knowledge and ability, no identifying images, or other personal or clinical details that are being presented, compromise anonymity; nonetheless, written informed consent was obtained from the patient for publication of this case report and any accompanying images.

\section{Conflict of Interest Statement}

The authors have no conflicts of interest to disclose.

\section{Karger'}




\section{Case Reports in Gastroenterology}

\section{Funding Sources}

No funding was obtained for this study.

\section{Author Contributions}

T.L.N., S.K., G.T.G., and M.E.F. conceptualized and wrote the manuscript. S.C.S.-H., G.T.G., and M.E.F. provided requisite images for figures and editorial guidance. All authors read and approved the finalized manuscript.

\section{References}

1 Mulholland KC, Wallace WD, Epanomeritakis E, Hall SR. Pseudocyst formation in gastric ectopic pancreas. JOP. 2004 Nov;5(6):498-501.

2 Matsushita M, Hajiro K, Okazaki K, Takakuwa H. Gastric aberrant pancreas: EUS analysis in comparison with the histology. Gastrointest Endosc. 1999 Apr;49(4 Pt 1):493-7.

3 Wall I, Shah T, Tangorra M, Li JJ, Tenner S. Giant heterotopic pancreas presenting with massive upper gastrointestinal bleeding. Dig Dis Sci. 2007 Apr;52(4):956-9.

4 Dolan RV, ReMine WH, Dockerty MB. The fate of heterotopic pancreatic tissue. A study of 212 cases. Arch Surg. 1974 Dec;109(6):762-5.

5 Sadeghi NR, Godambe A, Shienbaum AJ, Alloy A. Premalignant gastric heterotopic pancreas. Gastroenterol Hepatol (N Y). 2008 Mar;4(3):218-21.

6 Song DE, Kwon Y, Kim KR, Oh ST, Kim JS. Adenocarcinoma arising in gastric heterotopic pancreas: a case report. J Korean Med Sci. 2004 Feb;19(1):145-8.

7 Lucena JF, Alvarez OA, Gross GW. Endoscopic resection of heterotopic pancreas of the minor duodenal papilla: case report and review of the literature. Gastrointest Endosc. 1997 Jul;46(1):69-72.

8 Jin HB, Lu L, Yang JF, Lou QF, Yang J, Shen HZ, et al. Interventional endoscopic ultrasound for a symptomatic pseudocyst secondary to gastric heterotopic pancreas. World J Gastroenterol. 2017 Sep;23(34):6365-70.

9 Rodriguez AA, Berquist W, Bingham D. Gastric outlet obstruction caused by heterotopic pancreas in an adolescent. Dig Dis Sci. 2015 Apr;60(4):835-7.

10 Ayantunde AA, Pinder E, Heath DI. Symptomatic pyloric pancreatic heterotopia: report of three cases and review of the literature. Med Sci Monit. 2006 Jun;12(6):CS49-52. 
Case Reports in Gastroenterology
Case Rep Gastroenterol 2021;15:338-343

DOI: $10.1159 / 000512427$

C 2021 The Author(s). Published by S. Karger AG, Basel www.karger.com/crg

Nguyen et al.: Pancreatic Heterotopia Presenting as Gastric Outlet Obstruction
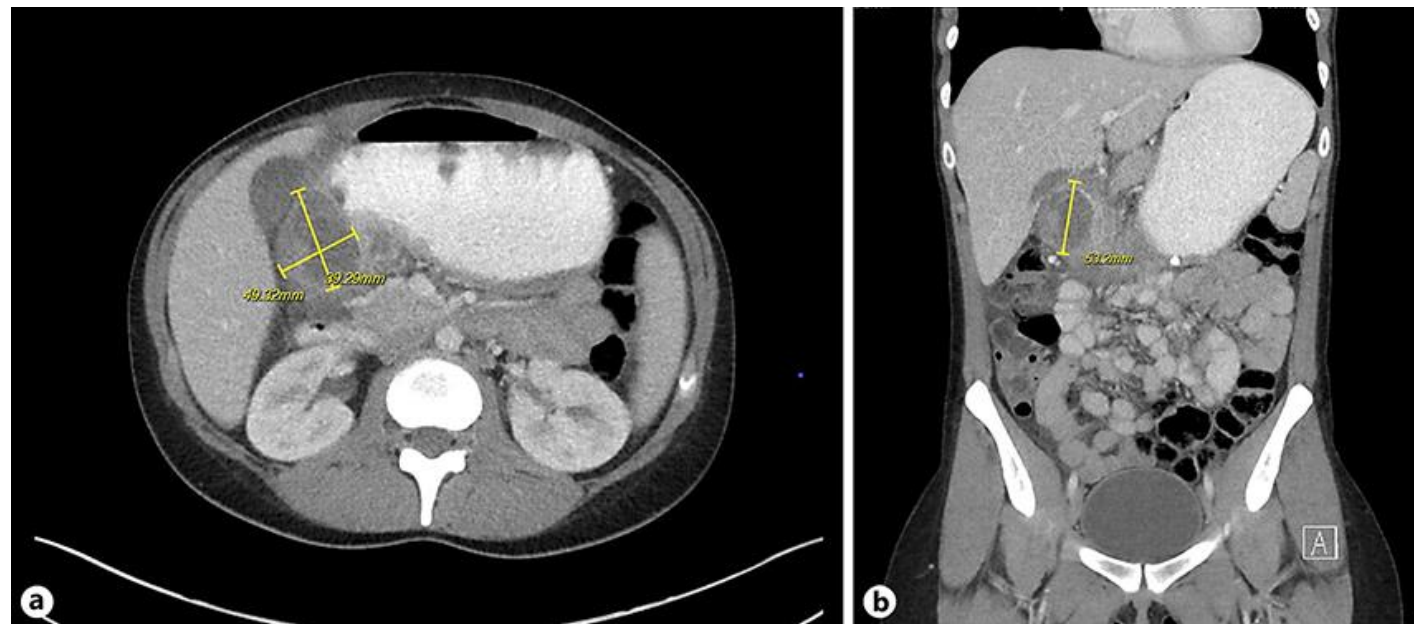

Fig. 1. CT of the abdomen, axial view (a) and coronal view (b), showing a $5.3 \times 4.9 \times 3.9 \mathrm{~cm}$, partly cystic mass abutting the pylorus.
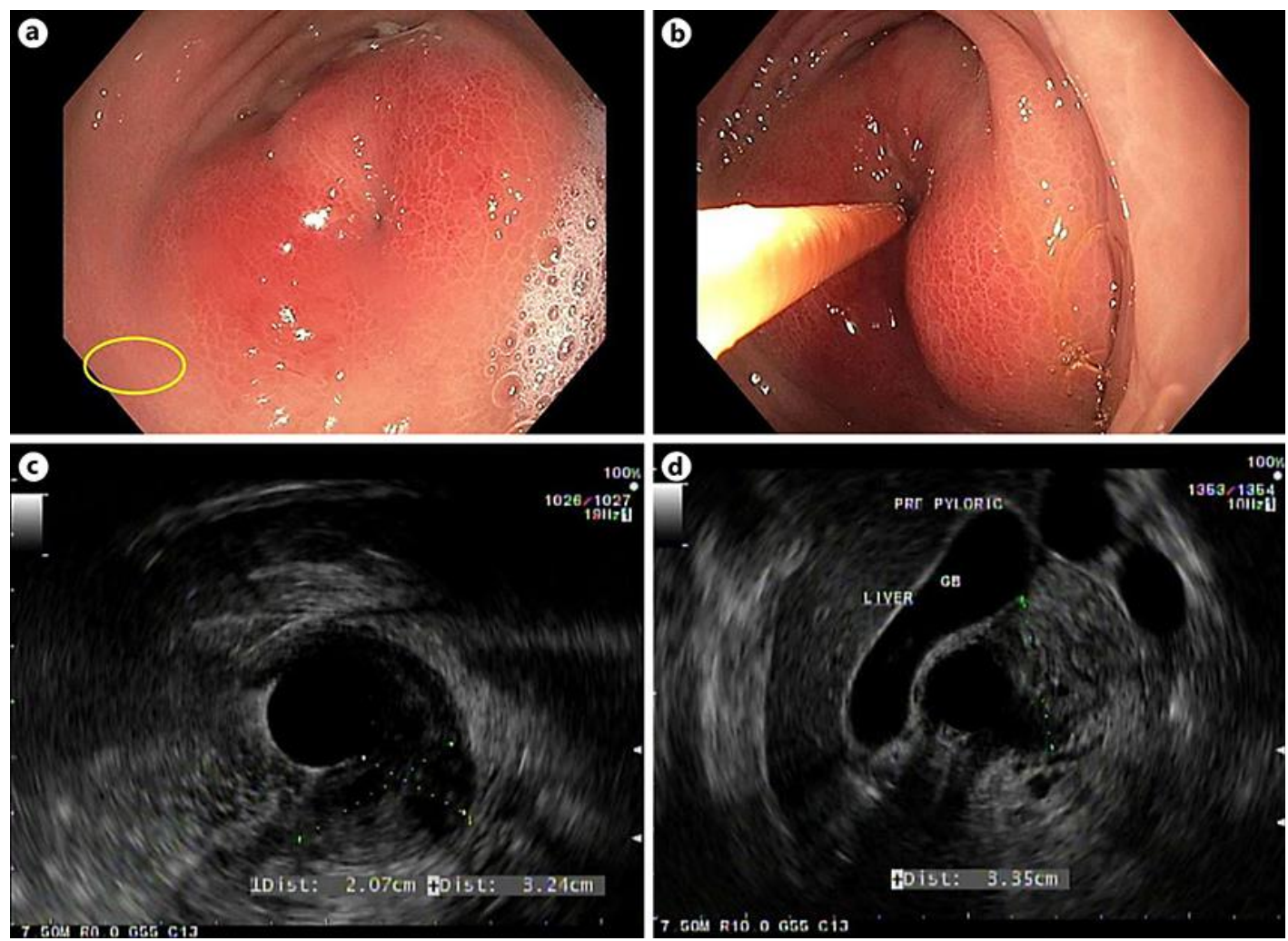

Fig. 2. Esophagogastroduodenoscopy visualization of the prepyloric, umbilicated mass with pillow sign (a, b). Endoscopic ultrasound showed a hypoechoic mass, with well-defined borders and without features suspicious of malignancy such as peripheral invasion. 
Case Reports in Gastroenterology
Case Rep Gastroenterol 2021;15:338-343

DOI: $10.1159 / 000512427$

(c) 2021 The Author(s). Published by S. Karger AG, Basel www.karger.com/crg

Nguyen et al.: Pancreatic Heterotopia Presenting as Gastric Outlet Obstruction
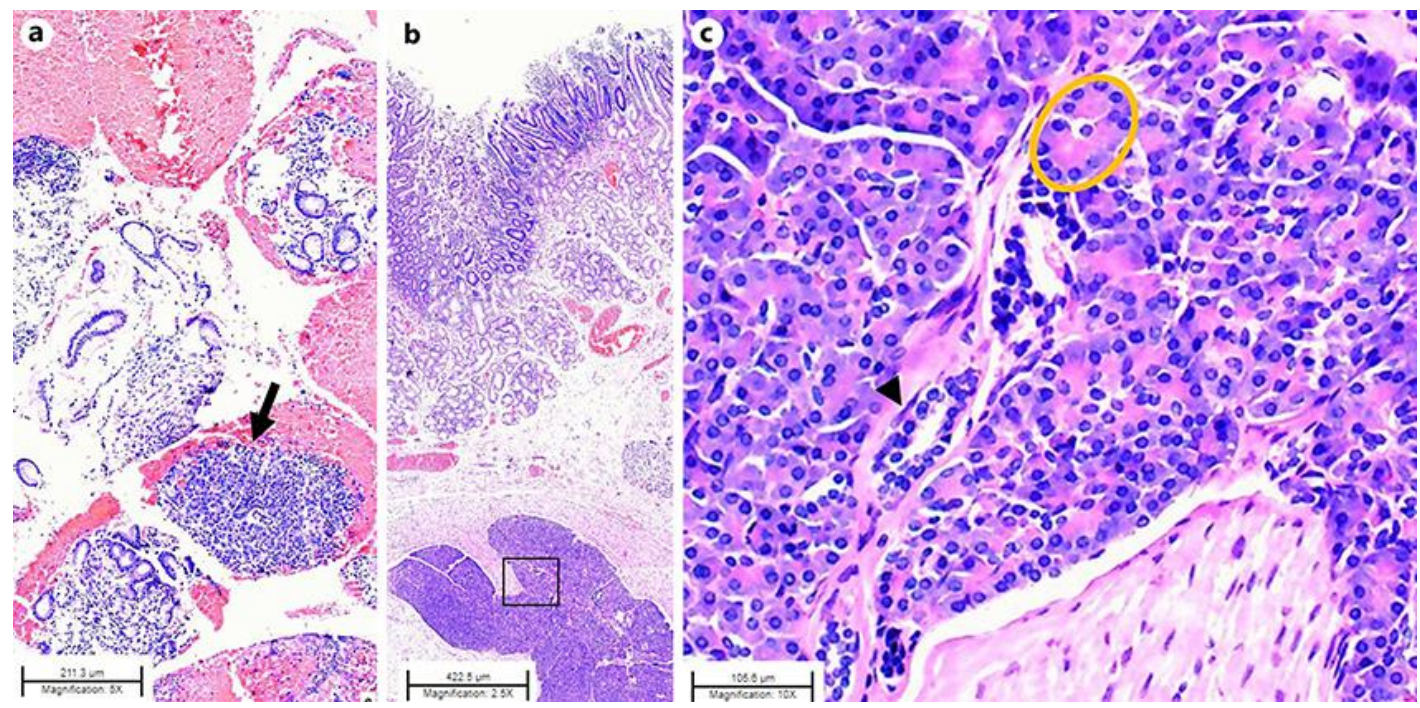

Fig. 3. a Diagnostic cytopathology cell block, showing normal exocrine pancreatic tissue (arrow), with background blood and gastric columnar mucosa. b, c Representative H\&E histopathology of the resection at $\times 2.5$ (b) and inset at $\times 10$ (c), showing a submucosal heterotopic pancreatic tissue with ducts (arrowhead) and normal exocrine acinar structures (yellow oval), but characteristic of type $2 \mathrm{PH}$, with no islets of Langerhans.

\section{Karger'}

